Review Article

\title{
Contribution of Interleukin-10-592 (-590, -597) C>A Polymorphisms to Periodontitis Susceptibility: An Updated Meta-Analysis Based on 18 Case-Control Studies
}

\author{
Yao Li, Ge Feng, Yuejia Deng, and Jinglin Song (iD \\ Department of Periodontology, Stomatological College, Chongqing Medical University, Chongqing 400016, China \\ Correspondence should be addressed to Jinglin Song; soongjl@163.com
}

Received 4 April 2018; Revised 2 July 2018; Accepted 15 July 2018; Published 19 September 2018

Academic Editor: Roberta Rizzo

Copyright (C) 2018 Yao Li et al. This is an open access article distributed under the Creative Commons Attribution License, which permits unrestricted use, distribution, and reproduction in any medium, provided the original work is properly cited.

\begin{abstract}
Introduction. The association between interleukin-10- (IL-10-) $592(-590,-597)$ C > A polymorphisms and susceptibility to chronic or aggressive periodontitis ( $\mathrm{CP}$ or $\mathrm{AgP})$ is conflicting. This meta-analysis is aimed at quantitatively estimating the association. Materials and Methods. PubMed, Embase, Web of Science, and WANFAN were searched for studies performed prior to January 31, 2018, to collect data for our research. Meta-analysis was performed using RevMan 5.3 or STATA 14.0. Results. In total, 18 studies that met our criteria were included. Overall or HWE subgroup analysis of individuals with this polymorphism revealed that in terms of $\mathrm{CP}$ susceptibility, there was a significant difference between case groups and control groups in the A allele versus $\mathrm{C}$ allele model $(\mathrm{OR}=1.38,95 \% \mathrm{CI}=1.17-1.64$ or $\mathrm{OR}=1.38,95 \% \mathrm{CI}=1.12-1.70)$, in the AA versus $\mathrm{CC}+\mathrm{CA}$ model $(\mathrm{OR}=1.49,95 \% \mathrm{CI}=1.06-2.10$ or $\mathrm{OR}=1.42,95 \% \mathrm{CI}=1.13-1.78)$, and in the $\mathrm{CC}$ versus $\mathrm{CA}+\mathrm{AA}$ model $(\mathrm{OR}=0.69,95 \%$ $\mathrm{CI}=0.51-0.92$ or $\mathrm{OR}=0.68,95 \% \mathrm{CI}=0.49-0.93)$; subgroup analysis based on a nonsmoking population also displayed significance in the A allele versus $\mathrm{C}$ allele model $(\mathrm{OR}=1.43,95 \% \mathrm{CI}=1.15-1.79)$ and $\mathrm{CC}$ versus $\mathrm{CA}+\mathrm{AA}$ model $(\mathrm{OR}=0.62,95 \%$ $\mathrm{CI}=0.44-0.87)$. For this polymorphisms and AgP susceptibility, our analyses revealed a significant association in both the A allele versus $\mathrm{C}$ allele model $(\mathrm{OR}=1.29,95 \% \mathrm{CI}=1.01-1.63)$ and the $\mathrm{AA}$ versus $\mathrm{CC}+\mathrm{CA}$ model $(\mathrm{OR}=1.93,95 \% \mathrm{CI}=1.30-2.89)$; subgroup analysis based on Caucasian or nonsmoking populations showed significant differences in the AA versus CC+CA model $(\mathrm{OR}=6.29,95 \% \mathrm{CI}=1.78-22.21$ or $\mathrm{OR}=3.24,95 \% \mathrm{CI}=1.59-6.61)$. Conclusions. $\mathrm{IL}-10-592(-590,-597)$ A allele and the associated AA genotype may be risk factors for the onset of $\mathrm{CP}$ or AgP-particularly for the AA genotype and the increased risk of AgP in Caucasian or nonsmoking populations. Conversely, the CC genotype may act as a protective factor against the onset of CP.
\end{abstract}

\section{Introduction}

It was previously reported that specific genetic factors can account for as much as $50 \%$ of the overall onset risks of periodontal disease $[1,2]$. Recently, gene polymorphisms in some cytokines such as interleukin- (IL-) 1 , IL-6, TNF- $\alpha$, IL-8, and IL-10 have been shown to play a vital role in the occurrence of both chronic and aggressive periodontitis ( $\mathrm{CP}$ and $\mathrm{AgP}$ ) immune pathogenesis [3-7].

IL-10 is an anti-inflammatory cytokine and a B lymphocyte proliferation factor, having pleiotropic effects on both immune regulation and inflammation [8]. It can stimulate the production of protective antibodies or autoimmunity proteins, while also being capable of downregulating the expression of proinflammatory cytokines, such as IL-1, IL-2, and IL-6 $[9,10]$. The IL-10 gene is located on chromosome 1q31-32 [11], and at its promoter region, there are three polymorphic loci, -1082 (-1087) A>G (rs1800896), $-819(-824) \mathrm{C}>\mathrm{T}(\mathrm{rs} 1800871)$, and $-592(-590,-597) \mathrm{C}>\mathrm{A}$ (rs1800872), that have been identified [12]. The A allele at the $-592(-590,-597)$ position is known to have a negative regulatory function [13].

Meta-analyses exclusively on the association of IL-10-592 $(-590,-597) \mathrm{C}>\mathrm{A}$ polymorphisms with periodontitis have 
not been extensively reported on, though two papers by Zhong et al. [14] and Albuquerque et al. [15] briefly touched on the topic as part of a larger body of work. Zhong et al. [14] used meta-analysis in 2012 to find out that the IL-10-592 $(-590,-597)$ A allele and AA genotype were significantly associated with an increased CP risk, while the A allele alone was significantly associated with CP risk in people of Caucasian ethnicity. However, Zhong et al. [14] did not investigate the association of IL-10-592 (-590, -597) gene polymorphisms with $\mathrm{AgP}$ risk. A meta-analysis by Albuquerque et al. [15] found out that the IL-10-592 (-590, -597) A allele was significantly associated with susceptibility to both $\mathrm{CP}$ and AgP. This was especially true for susceptibility to CP in Caucasian individuals. Albuquerque et al. [15] also found out that the CC genotype at this locus was associated with resistance to $\mathrm{CP}$ onset in Caucasian population. Importantly, the two meta-analyses only included studies conducted before 2009 and thus only involved in six studies that included $624 \mathrm{CP}$ cases and 623 controls [16-21] and five studies that included $411 \mathrm{CP}$ cases, $97 \mathrm{AgP}$ cases, and 442 controls [16-20], respectively. Since that time, there have been another 12 studies [22-33] reporting the association between IL-10-592 $(-590,-597)$ C >A polymorphisms and periodontitis susceptibility, though the findings have been inconsistent. Therefore, in the present meta-analysis, we include a total of 18 studies [16-33] to further identify the contributions of IL-10-592 $(-590,-597)$ gene variations to periodontitis $(\mathrm{CP} / \mathrm{AgP})$ susceptibility in a larger number and range of patients.

\section{Materials and Methods}

The meta-analysis was performed in accordance with the PRISMA-P (preferred reporting items for systematic reviews and meta-analysis protocols) statement which was recommended for the establishment of a systematic review and meta-analysis [34].

2.1. Focused Question. Is there an association between IL-10$592(-590,-597)$ gene variations and $\mathrm{CP}$ or $\mathrm{AgP}$ ?

2.2. Inclusion Criteria. The inclusion criteria that published studies need to meet to be included in the meta-analysis were as follows: (1) case-control studies; (2) the case groups consisted of patients diagnosed with CP or AgP, and the control groups consisted of periodontally healthy individuals; (3) IL10-592 (-590, -597) C>A polymorphisms were detected, and sufficient data regarding genotype distributions were provided for the calculation of odds ratio (ORs) and corresponding 95\% confidence intervals (95\% CIs); and (4) studies with no repeated data. Studies that did not meet each of these criteria were excluded from the meta-analysis.

2.3. Search Strategy. A systematic literature search for studies published up to January 31,2018 , was performed using the electronic databases, PubMed, Embase, Web of Science, and WANFAN. In addition, the reference lists of the selected manuscripts and related reviews were also manually screened for comprehensive results. The search strategies were presented as follows.

\subsubsection{Search Strategies}

(1) PubMed. Periodontal Diseases or Periodontitis or Periodontics or periodontal disease (title/abstract) or periodontitis (title/abstract) or periodontal pocket (title/abstract) or periodontal tissue (title/abstract) and Interleukin-10 or Interleukin-10 (title/abstract) or title/abstract (all fields) or IL-10 (title/abstract) or IL 10 (title/abstract) or Interleukin 10 (title/abstract) and polymorphism, genetic or genetic variation or polymorphism (title/abstract) or polymorphisms (title/abstract) or genetic variation (title/abstract) or rs1800872 (title/abstract).

(2) Embase. Periodontal disease/exp or periodontitis/exp or periodontics/exp or periodontal disease: $\mathrm{ab}$, ti or periodontitis: $a b$, ti or periodontal pocket: $a b$, ti or periodontal tissue: ab, ti and Interleukin $10^{\prime}$ /exp or Interleukin 10: ab, ti or IL10: ab, ti or rs1800872: ab, ti and DNA polymorphism/ exp or genetic variability/exp or polymorphism: ab, ti or polymorphisms: ab, ti or genetic variation: $a b$, ti.

\section{(3) Web of Science.}

Number 1

$\mathrm{TS}=$ periodontal disease or

TS $=$ periodontitis or $\mathrm{TS}=$ periodontal pocket or

TS $=$ periodontal tissue

Number 2

TS $=$ interleukin -10 or TS $=$ IL-10 or TS $=$ interleukin 10

or TS $=$ IL 10

Number 3

$\mathrm{TS}=$ polymorphism or

TS $=$ polymorphisms or TS $=$ genetic variation

Number 1 and Number 2 and Number 3

(4) WANFAN. Keywords in Chinese were used for the systematic search as follows: periodontal diseases, periodontitis, IL-10, interleukin-10, polymorphism, and the combined phrases.

2.4. Study Selection and Data Extraction. For study selection, duplicate studies or datasets were firstly removed from the included titles using EndNote software. Then titles and abstracts of the remaining results were screened, followed by full-text paper screening according to the inclusion criteria described above (Figure 1). The results were screened by two authors independently, and a third author (JL Song) was consulted if any discrepancies existed. The following characteristics were extracted from the included studies by two authors independently, and discrepancies were resolved through discussion as follows: (1) the name of the first author and year of publication, (2) country (or district) and ethnicity of study participants, (3) group size, (4) smoking status, (5) gender ratio comparability, (6) type of controls, (7) genotype distribution, and (8) the Hardy-Weinberg equilibrium (HWE) results for the controls.

2.5. Quality Assessment. The Newcastle-Ottawa Scale (NOS) was used to assess the quality of the included case-control studies, which was performed by two authors independently. 


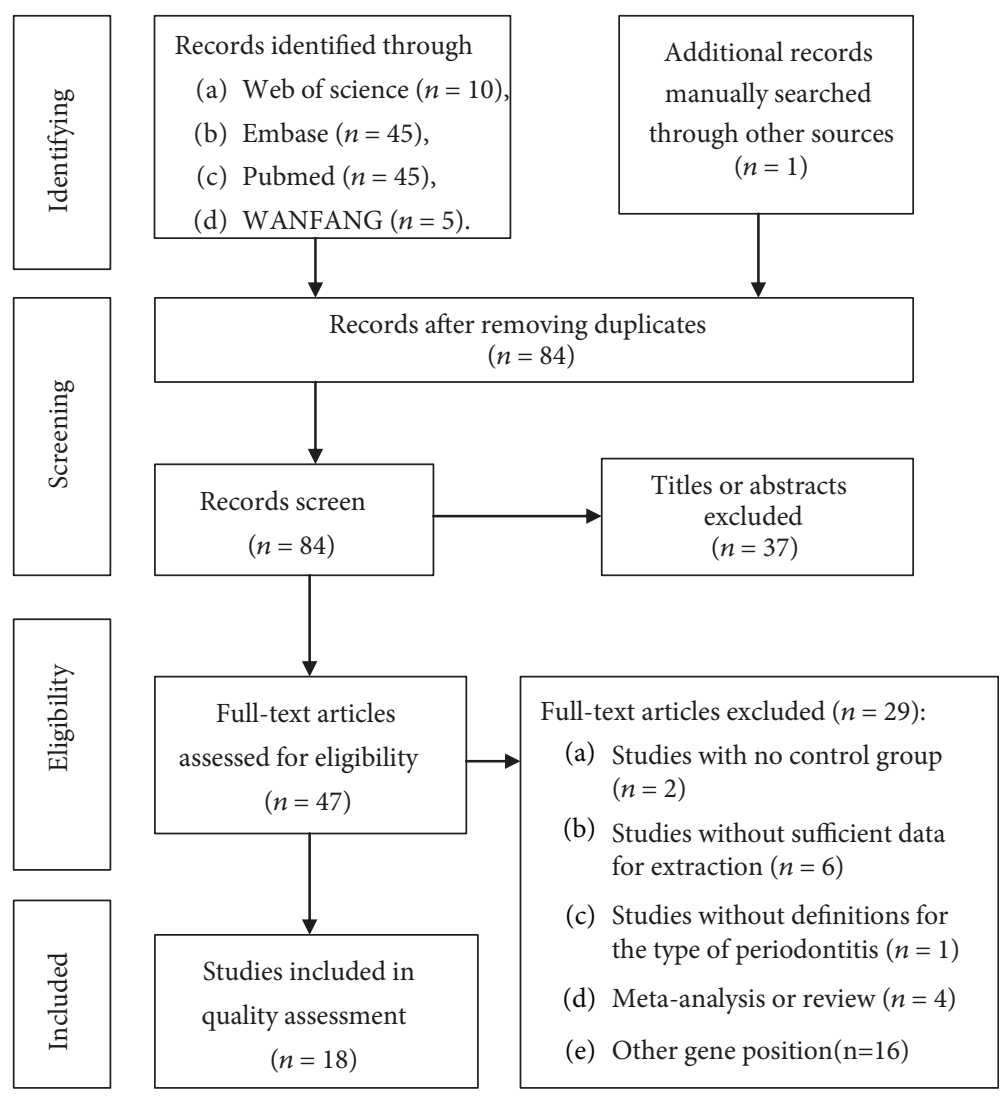

Figure 1: Screening process of the included studies.

The composition of NOS includes three sections for consideration, which were "Selection" (0-4 points), "Comparability" (0-2 points), and "Exposure" (0-3 points). For the "Comparability" chapter, smoking status, age, and sex were selected as the main confounding factors to be matched in the present study. If two out of three factors were matched, one point (asterisk) was scored; if all three factors were matched, two points were assigned. The final scores were calculated ranging from 0 to 9 . Studies with scores of $0-3,4-6$, and 7-9 points were considered of low, moderate, and high quality, respectively $[6,35]$.

2.6. Data Analysis. The ORs and 95\% CIs were calculated to evaluate the association between IL-10-592 (-590, -597) polymorphisms and susceptibility to chronic or aggressive periodontitis. Heterogeneity between studies was estimated by $\chi^{2}$ and $I^{2}$. An $I^{2}>50 \%$ or $P<0.05$ was considered to have significant heterogeneity. Next, the Mantel-Haenszel random effects model was used to assure the pooled efficiency. Otherwise, the Mantel-Haenszel fixed-effects model was used. The following three genetic models were applied for the meta-analyses of the IL-10-592 (-590, -597) polymorphisms: (1) allele comparison, (2) the dominant model, and (3) the recessive model. In addition, the $\chi^{2}$ test method was used to assess the Hardy-Weinberg equilibrium (HWE) for the control groups. Subgroup analyses were conducted based on ethnicity, HWE fulfillment, and smoking status. The potential publication bias was measured by Begg's and Egger's linear regression tests. A publication bias was considered significant if $P<0.05$. All statistical analyses were processed using the statistical software RevMan (version 5.3; The Nordic Cochrane Centre, The Cochrane Collaboration, Copenhagen, Denmark, 2014) or STATA 14.0.

\section{Results}

3.1. Characteristics and Quality Assessment of Included Studies. A total of 18 articles were included in the current meta-analysis on the gene IL-10-592 (-590, -597) C>A (rs1800872) polymorphisms. The selection process for including publication articles is presented in the flowchart (Figure 1). The characteristics of included studies are presented in Table 1. As shown in Table 1, 18 studies encompassing 2191 cases (1903 CP cases and 288 AgP cases) and 1975 controls were involved in the analysis of associations between IL-10-592 (-590, -597) C>A polymorphisms and the occurrence of either CP or AgP. Caucasian individuals alone were the focus of seven studies. Claudino et al. [18] and Garlet et al. [23] recruited a mixed population for their study, containing both Caucasian individuals and AfricanAmericans as research subjects. Eleven studies documented nonsmokers in CP and AgP cases and controls. Allelic and genotypic data of IL-10-592 $(-590,-597) \mathrm{C}>\mathrm{A}$ are shown in Table 1. With the exception of studies by Garlet et al. [23], Gorgun et al. [29], Toker et al. [30, 33], and Moudi et al. [32], the genotype distributions in the control groups of the other studies were consistent with HWE. 
TABLE 1: Characteristics of the included studies on association of IL-10-592 (-590, -597) C>A gene polymorphisms with periodontitis.

\begin{tabular}{|c|c|c|c|c|c|c|c|c|}
\hline Author (year) & Population & Study type & Cases/controls & $\begin{array}{c}\text { Smoking } \\
\text { status }\end{array}$ & $\begin{array}{l}\text { Control } \\
\text { type }\end{array}$ & Gender & $\begin{array}{l}\text { Quality } \\
\text { (NOS) }\end{array}$ & $\begin{array}{l}\text { Locus } \\
\text { of SNPs }\end{array}$ \\
\hline $\begin{array}{l}\text { Scarel-Caminaga et al. } \\
\text { (2004) [16] }\end{array}$ & $\begin{array}{l}\text { Brazilian } \\
\text { Caucasian }\end{array}$ & Case-control & $48 / 36$ & No smoke & $\mathrm{HC}$ & Matched & $7 / 9$ & -592 \\
\hline Sumer et al. (2007) [17] & Turkish Caucasian & Case-control & $75 / 73$ & No smoke & CC & Matched & $8 / 9$ & -597 \\
\hline Claudino et al. (2008) [18] & Brazilian (mixed) & Case-control & $116 / 173$ & No smoke & $\mathrm{CC}$ & $\begin{array}{c}\text { Not } \\
\text { Matched }\end{array}$ & $6 / 9$ & -592 \\
\hline Reichert et al. (2008) [19] & German Caucasian & Case-control & $59 / 34$ & Mixed & $\mathrm{CC}$ & Matched & $6 / 9$ & -590 \\
\hline Hu et al. (2009) [20] & Taiwanese Han & Case-control & $210 / 126$ & Mixed & $\mathrm{HC}$ & Matched & $5 / 9$ & -592 \\
\hline Li et al. (2009) [21] & Chinese Han & Case-control & $30 / 30$ & Unknown & $\mathrm{HC}$ & Matched & $6 / 9$ & -592 \\
\hline $\begin{array}{l}\text { Atanasovska-Stojanovska et al. } \\
\text { (2012) [22] }\end{array}$ & $\begin{array}{c}\text { Macedonian } \\
\text { Caucasian }\end{array}$ & Case-control & $111 / 299$ & No smoke & $\mathrm{HC}$ & Matched & $7 / 9$ & -592 \\
\hline Garlet et al. (2012) [23] & Brazilian (mixed) & Case-control & $197 / 214$ & No smoke & $\mathrm{HC}$ & Matched & $7 / 9$ & -592 \\
\hline Jaradat et al. (2012) [24] & Jordanian & Case-control & $190 / 86$ & No smoke & CC & Matched & $7 / 9$ & -597 \\
\hline Scapoli et al. (2012) [25] & Italian Caucasian & Case-control & $182 / 230$ & Mixed & Unknown & Unknown & $5 / 9$ & -592 \\
\hline Scapoli et al. (2015) [26] & Italian Caucasian & Case-control & $182 / 230$ & No smoke & Unknown & Matched & $6 / 9$ & -592 \\
\hline Silveira et al. (2016) [27] & Brazilian & Case-control & $111 / 61$ & No smoke & $\mathrm{HC}$ & Matched & $6 / 9$ & -592 \\
\hline Gorgun et al. (2017) [29] & Turkish & Case-control & $53 / 50$ & No smoke & $\mathrm{HC}$ & Matched & $7 / 9$ & -597 \\
\hline Lopes et al. (2017) [28] & Brazilian & Case-control & $55 / 150$ & Unknown & $\mathrm{HC}$ & Matched & $4 / 9$ & -592 \\
\hline Toker et al. (2017) [30] & Turkish Caucasian & Case-control & $103 / 38$ & No smoke & $\mathrm{HC}$ & Matched & $6 / 9$ & -597 \\
\hline Zhang et al. (2017) [31] & Chinese Uygur & Case-control & $200 / 100$ & Unknown & $\mathrm{CC}$ & Matched & $7 / 9$ & -597 \\
\hline Moudi et al. (2018) [32] & Iranian & Case-control & $210 / 100$ & No smoke & $\mathrm{HC}$ & Matched & $7 / 9$ & -592 \\
\hline Toker et al. (2018) [33] & Turkish & Case-control & $52 / 50$ & No smoke & $\mathrm{HC}$ & Matched & $7 / 9$ & -592 \\
\hline
\end{tabular}

HC/CC: hospital/community control; NOS: Newcastle-Ottawa scale; SNPs: single-nucleotide polymorphisms.

The scores of NOS ranged from 4 to 8 . Nine studies were considered to be of high quality $[16,17,22-24,29,30,32,33]$, and the other 9 studies were classed as moderate quality [18-21, 25-28, 31] (Table 2, e-Table 1).

3.2. Meta-Analysis Results of Association between IL-10-592 (-590, -597) C>A Polymorphisms and the Risk of CP. Our literature search yielded 16 viable studies that had been conducted on the association between IL-10-592 (-590, -597) $\mathrm{C}>\mathrm{A}$ polymorphisms and the risk of acquiring CP. The results are summarized in Table 3 . We found out that there were significant associations in the A allele versus $\mathrm{C}$ allele model $(\mathrm{OR}=1.38,95 \% \mathrm{CI}=1.17-1.64)$, in the AA versus $\mathrm{CC}+\mathrm{CA}$ model (recessive model; $\mathrm{OR}=1.49$, 95\% CI $=1.06-$ 2.10), and in the CC versus CA+AA model (dominant model; $\mathrm{OR}=0.69,95 \% \mathrm{CI}=0.51-0.92$ ) (Table 3 ). When stratified by HWE, significant differences were also found in the A allele versus $\mathrm{C}$ allele model $(\mathrm{OR}=1.38,95 \% \mathrm{CI}=1.12-1.70)$, in the $\mathrm{AA}$ versus $\mathrm{CC}+\mathrm{CA}$ model $(\mathrm{OR}=1.42,95 \% \mathrm{CI}=1.13-$ $1.78)$, and in the $C C$ versus $C A+A A$ model $(O R=0.68,95 \%$ $\mathrm{CI}=0.49-0.93)$. In this analysis, we excluded the studies by Garlet et al. [23], Toker et al. [30, 33], and Moudi et al. [32], as genotype distributions in their control groups were deviated from HWE (Table 3, Figures 2(a)-2(c)).

When we considered only the Caucasian subgroup, we found no significant differences in the $\mathrm{A}$ allele versus $\mathrm{C}$ allele model, in the AA versus CC+CA model, or in the CC versus $\mathrm{CA}+\mathrm{AA}$ model (Table 3). Conversely, in the nonsmoker subgroup, we did find significant differences in both the A allele versus $\mathrm{C}$ allele model $(\mathrm{OR}=1.43,95 \% \mathrm{CI}=1.15-1.79)$ and $\mathrm{CC}$ versus $\mathrm{CA}+\mathrm{AA}$ model $(\mathrm{OR}=0.62,95 \% \mathrm{CI}=0.44-0.87)$ (Table 3, Figures 3(a) and 3(c)).

3.3. Meta-Analysis Results of Association between IL-10-592 (-590, -597) C>A Polymorphisms and the Risk of AgP. Six studies were involved, comprising 288 cases and 399 controls. The results are summarized in Table 3 . The overall analyses of these studies yielded significant estimates in the $\mathrm{A}$ allele versus $\mathrm{C}$ allele model $(\mathrm{OR}=1.29,95 \% \mathrm{CI}=1.01-$ 1.63 ) and in the AA versus CC+CA model (OR $=1.93,95 \%$ $\mathrm{CI}=1.30-2.89$ ) (Table 3, Figures 4 (a) and 4(b)) but no significant estimates in the CC versus CA+AA model (Table 3). Subgroup analyses by ethnicity showed significant trends in the Caucasian population in the A allele versus $\mathrm{C}$ allele model $(\mathrm{OR}=1.55,95 \% \mathrm{CI}=0.97-2.48)$ and significant differences in the $\mathrm{AA}$ versus $\mathrm{CC}+\mathrm{CA}(\mathrm{OR}=6.29,95 \% \mathrm{CI}=1.78-22.21)$ (Table 3, Figure 4(c)), but no significant estimates were found in the CC versus CA+AA model (Table 3). The nonsmoker subgroup analysis did, however, reveal significant differences in the AA versus $\mathrm{CC}+\mathrm{CA}$ model $(\mathrm{OR}=3.24,95 \% \mathrm{CI}=1.59$ 6.61) (Table 3, Figure 4(d)).

3.4. Sensitivity Analysis. To assess the effect of an individual dataset on pooled ORs, a sensitivity analysis was performed through the sequential omission of each study. The results suggested that no single study greatly influenced the pooled estimations under any of the three genetic models for $\mathrm{CP}$ (e-Tables 2-4). 
TABLE 2: Distribution of IL-10-592 (-590, -597) C>A genotypes and allele frequency among periodontitis patients and control subjects.

\begin{tabular}{|c|c|c|c|c|c|c|c|c|c|c|c|c|c|c|}
\hline \multirow{3}{*}{ First author } & \multirow{3}{*}{ Year } & \multirow{3}{*}{ Cases $(\mathrm{CP} / \mathrm{AgP})$} & \multirow{3}{*}{ Controls } & \multicolumn{6}{|c|}{ Genotype distribution } & \multicolumn{4}{|c|}{ Allele distribution } & \multirow{3}{*}{$\begin{array}{c}P \text { for HWE } \\
\text { (control) }\end{array}$} \\
\hline & & & & \multicolumn{3}{|c|}{ Cases } & \multicolumn{3}{|c|}{ Controls } & \multicolumn{2}{|c|}{ Cases } & \multicolumn{2}{|c|}{ Controls } & \\
\hline & & & & $\mathrm{CC}$ & $\mathrm{AC}$ & $\mathrm{AA}$ & $\mathrm{CC}$ & $\mathrm{AC}$ & $\mathrm{AA}$ & $\mathrm{C}$ & A & $\mathrm{C}$ & $\mathrm{A}$ & \\
\hline Scarel-Caminaga [16] & 2004 & 48 (CP) & 36 & 12 & 34 & 2 & 19 & 14 & 3 & 58 & 38 & 52 & 20 & 0.85 \\
\hline Sumer [17] & 2007 & $75(\mathrm{CP})$ & 73 & 24 & 40 & 11 & 43 & 29 & 1 & 88 & 62 & 115 & 31 & 0.11 \\
\hline Claudino [18] & 2008 & $116(\mathrm{CP})$ & 173 & 33 & 65 & 18 & 84 & 69 & 20 & 131 & 101 & 237 & 109 & 0.32 \\
\hline \multirow{2}{*}{ Reichert [19] } & \multirow{2}{*}{2008} & $27(\mathrm{CP})$ & \multirow{2}{*}{34} & 20 & 7 & 0 & \multirow{2}{*}{23} & \multirow{2}{*}{10} & \multirow{2}{*}{1} & 47 & 7 & \multirow{2}{*}{56} & \multirow{2}{*}{12} & \multirow{2}{*}{0.94} \\
\hline & & $32(\mathrm{AgP})$ & & 18 & 8 & 6 & & & & 44 & 20 & & & \\
\hline \multirow{2}{*}{$\mathrm{Hu}[20]$} & \multirow{2}{*}{2009} & $145(\mathrm{CP})$ & \multirow{2}{*}{126} & 27 & 32 & 86 & \multirow{2}{*}{16} & \multirow{2}{*}{48} & \multirow{2}{*}{62} & 86 & 204 & \multirow{2}{*}{80} & \multirow{2}{*}{172} & \multirow{2}{*}{0.17} \\
\hline & & $65(\mathrm{AgP})$ & & 6 & 21 & 38 & & & & 33 & 97 & & & \\
\hline $\operatorname{Li}[21]$ & 2009 & $30(\operatorname{AgP})$ & 30 & 7 & 11 & 12 & 5 & 12 & 13 & 25 & 35 & 22 & 38 & 0.275 \\
\hline Atanasovska-Stojanovska [22] & 2012 & $111(\mathrm{CP})$ & 299 & 62 & 45 & 4 & 154 & 117 & 28 & 169 & 53 & 425 & 173 & 0.40 \\
\hline Scapoli $[25]$ & 2012 & $178(\mathrm{CP})$ & 222 & 75 & 83 & 20 & 115 & 91 & 16 & 233 & 123 & 321 & 123 & 0.73 \\
\hline Garlet [23] & 2012 & $197(\mathrm{CP})$ & 214 & 57 & 107 & 33 & 106 & 80 & 28 & 221 & 173 & 292 & 136 & 0.04 \\
\hline Jaradat [24] & 2012 & $105(\mathrm{CP})$ & 86 & 60 & 32 & 13 & 63 & 19 & 4 & 152 & 58 & 145 & 27 & 0.13 \\
\hline Scapoli [26] & 2015 & $279(\mathrm{CP})$ & 213 & 143 & 109 & 27 & 114 & 83 & 16 & 395 & 163 & 311 & 115 & 0.87 \\
\hline Silveira [27] & 2016 & $61(\mathrm{CP})$ & 61 & 22 & 32 & 7 & 27 & 26 & 8 & 76 & 46 & 80 & 42 & 0.66 \\
\hline & 2010 & $50(\mathrm{AgP})$ & 01 & 20 & 21 & 9 & 21 & 20 & 0 & 61 & 39 & ou & 42 & 0.00 \\
\hline Gorgun [29] & 2017 & $53(\mathrm{AgP})$ & 50 & 7 & 34 & 12 & 3 & 45 & 2 & 48 & 58 & 51 & 49 & $<0.001$ \\
\hline Lopes [28] & 2017 & $55(\mathrm{CP})$ & 150 & 0 & 42 & 13 & 48 & 83 & 19 & 42 & 68 & 179 & 121 & 0.07 \\
\hline Toker [30] & 2017 & $45(\mathrm{CP})$ & 38 & 5 & 24 & 16 & 2 & 34 & 2 & 34 & 56 & 38 & 38 & $<0001$ \\
\hline $10 \mathrm{Ker}[30]$ & 2017 & $50(\mathrm{AgP})$ & 38 & 6 & 38 & 14 & 2 & 34 & 2 & 50 & 66 & 38 & 38 & $<0.001$ \\
\hline Zhang [31] & 2017 & 199 (CP) & 100 & 54 & 95 & 50 & 29 & 52 & 19 & 203 & 195 & 110 & 90 & 0.96 \\
\hline Moudi [32] & 2018 & $210(\mathrm{CP})$ & 100 & 12 & 152 & 46 & 10 & 61 & 29 & 176 & 214 & 81 & 119 & 0.008 \\
\hline Toker [33] & 2018 & $52(\mathrm{CP})$ & 50 & 7 & 27 & 18 & 3 & 45 & 2 & 41 & 63 & 61 & 49 & $<0.001$ \\
\hline
\end{tabular}

CP/AgP: chronic/aggressive periodontitis; HWE: Hardy-Weinberg equilibrium fulfillment.

3.5. Publication Bias. Egger's test proved that there was no significant publication bias except HWE fulfillment or Caucasian population subgroup analysis in the CP versus controls allele comparison (Table 3). There was also not any obvious evidence of publication bias by Egger's test in overall and subgroup analysis in the AgP versus controls alleles and genotypes comparison (Table 3 ).

\section{Discussion}

4.1. Summary of Evidence. The present meta-analysis included 18 studies with 2191 cases and 1975 controls. There are some conflicting results among the 18 studies included, which may be the result of variations in individual study characteristics, including the ethnic populations surveyed, different sample sizes, and key confounding variables such as smoking status. Therefore, the present meta-analysis increases the likelihood of identifying true correlations by further systematizing the existing information.

Investigations of the correlations between IL-10-592 $(-590,-597) \mathrm{C}>\mathrm{A}$ polymorphisms and CP risk suggested that IL-10-592 (-590, -597) A allele and AA genotype may increase the risk of $\mathrm{CP}$, while $\mathrm{CC}$ genotype provides increased protection against the risk of the disease. These results were expected because 11 out of 16 individual studies included in our meta-analysis presented these trends in their populations. Furthermore, sensitivity analysis revealed no quantitative changes for the interstudy heterogeneity, suggesting that these results were stable and trustworthy.

It was demonstrated that the associations between genetic polymorphisms and certain diseases varied with different geographical regions and ethnic groups [6]. Therefore, we also investigated the contributions of ethnicity to the risk of disease. Our results suggested that the IL-10-592 (-590, -597) A allele and AA or CC genotypes were not associated with any increased risk that Caucasian individuals may have toward CP. These results varied from the meta-analysis results reported by Zhong et al. [14] and Albuquerque et al. [15] in which they found out that the A allele might increase the risk for CP, and Albuquerque et al. [15] found out the CC genotype might resist the risk among Caucasians. We hypothesize that part of the reason for this variation is that our meta-analysis included four additional studies that yielded inconsistent results [22, 25, 26, 30].

For IL-10-592 (-590, -597) C>A polymorphisms and $\mathrm{AgP}$, our meta-analysis results indicated that the A allele may confer a relative increase in the risk for developing AgP, especially in Caucasian individuals, as described in the meta-analysis results reported by Albuquerque et al. [15]. The same conclusions can be drawn in relation to the comparison AA versus AC/CC genotypes, which is in contrast to the results reported by Albuquerque et al. [15].

Smoking may increase the risk of periodontitis onset [36-38], so we performed nonsmoker subgroup analyses 
TABLe 3: IL-10-592 (-590, -597) C>A polymorphism and periodontitis.

\begin{tabular}{|c|c|c|c|c|c|c|c|c|}
\hline Genetic model & Total/subgroup & $\begin{array}{l}\text { Number } \\
\text { of studies }\end{array}$ & Cases/controls & OR ( $P$ value $)$ & $95 \% \mathrm{CI}$ & $\begin{array}{c}I^{2}, \% \\
\left(P \text { value }^{\mathrm{a}}\right)\end{array}$ & $\begin{array}{c}\text { Egger } \\
(P \text { value })\end{array}$ & $\begin{array}{c}\text { Model of } \\
\text { meta-analysis }\end{array}$ \\
\hline \multicolumn{9}{|c|}{ IL-10-592 (-590, -597) C>A polymorphism and chronic periodontitis } \\
\hline \multirow{4}{*}{ A versus $\mathrm{C}$} & Total & 16 & $1903 / 1975$ & $1.38(<0.001)$ & $1.17-1.64$ & $62.1(0.001)$ & 0.071 & Random \\
\hline & Total for $\mathrm{HWE}^{\mathrm{b}}$ & 12 & $1418 / 1580$ & $1.38(0.002)$ & $1.12-1.70$ & $65.9(<0.001)$ & 0.017 & Random \\
\hline & Caucasian & 7 & $763 / 915$ & $1.31(0.088)$ & $0.96-1.77$ & $68.4(0.004)$ & 0.047 & Random \\
\hline & Nonsmoker & 11 & $1299 / 1343$ & $1.43(0.002)$ & $1.15-1.79$ & $68.0(<0.001)$ & 0.294 & Random \\
\hline \multirow{4}{*}{$\mathrm{AA}$ versus $\mathrm{CC}+\mathrm{CA}$} & Total & 16 & $1903 / 1975$ & $1.49(0.02)$ & $1.06-2.10$ & $59.4(0.001)$ & 0.243 & Random \\
\hline & Total for HWE & 12 & $1399 / 1573$ & $1.42(0.002)$ & $1.13-1.78$ & $31.0(0.14)$ & 0.234 & Fixed \\
\hline & Caucasian & 7 & $763 / 915$ & $1.50(0.33)$ & $0.66-3.43$ & $68.0(0.005)$ & 0.647 & Random \\
\hline & Nonsmoker & 11 & $1299 / 1343$ & $1.56(0.10)$ & $0.91-2.66$ & $71.0(<0.001)$ & 0.993 & Random \\
\hline \multirow{4}{*}{$\mathrm{CC}$ versus $\mathrm{AA}+\mathrm{CA}$} & Total & 16 & $1903 / 1975$ & $0.69(0.01)$ & $0.51-0.92$ & $68.0(<0.001)$ & 0.208 & Random \\
\hline & Total for HWE & 12 & $1399 / 1573$ & $0.68(0.02)$ & $0.49-0.93$ & $69.0(<0.001)$ & 0.149 & Random \\
\hline & Caucasian & 7 & $763 / 915$ & $0.74(0.15)$ & $0.50-1.11$ & $66.2(0.007)$ & 0.676 & Random \\
\hline & Nonsmoker & 11 & $1299 / 1343$ & $0.62(0.006)$ & $0.44-0.87$ & $68.0(<0.001)$ & 0.450 & Random \\
\hline \multicolumn{9}{|c|}{ IL-10-592 $(-590,-597)$ C>A polymorphism and aggressive periodontitis } \\
\hline \multirow{4}{*}{ A versus $\mathrm{C}$} & Total & 6 & $288 / 399$ & $1.29(0.04)$ & $1.01-1.63$ & $0.0(0.69)$ & 0.28 & Fixed \\
\hline & Caucasian & 2 & $90 / 72$ & $1.55(0.07)$ & $0.97-2.48$ & $0.0(0.35)$ & - & Fixed \\
\hline & Nonsmoker & 3 & $161 / 149$ & $1.26(0.157)$ & $0.92-1.74$ & $0.0(0.98)$ & - & Fixed \\
\hline & Total & 6 & $288 / 399$ & $1.93(0.001)$ & $1.30-2.89$ & $47.5(0.09)$ & - & Fixed \\
\hline \multirow[t]{3}{*}{$\mathrm{AA}$ versus $\mathrm{CC}+\mathrm{CA}$} & Caucasian & 2 & $90 / 72$ & $6.29(0.004)$ & $1.78-22.21$ & $0.0(0.83)$ & - & Fixed \\
\hline & Nonsmoker & 3 & $161 / 149$ & $3.24(0.001)$ & $1.59-6.61$ & $47.0(0.15)$ & - & Fixed \\
\hline & Total & 6 & $288 / 399$ & $0.98(0.91)$ & $0.64-1.49$ & $0.0(0.52)$ & 0.43 & Fixed \\
\hline \multirow[t]{2}{*}{$\mathrm{CC}$ versus $\mathrm{AA}+\mathrm{CA}$} & Caucasian & 2 & $90 / 72$ & $0.88(0.76)$ & $0.39-2.01$ & $34.0(0.22)$ & - & Fixed \\
\hline & Nonsmoker & 3 & $161 / 149$ & $1.19(0.58)$ & $0.65-2.17$ & $5.6(0.35)$ & - & Fixed \\
\hline
\end{tabular}

OR: odds ratio; CI: confidence interval. ${ }^{\mathrm{a}} \mathrm{P}$ value for heterogeneity. ${ }^{\mathrm{b}} \mathrm{Hardy}-$ Weinberg equilibrium fulfillment.

in order to account for the effect of smoking status on the risk of developing CP or AgP. Our findings confirmed that there was a significant association between the occurrence of the $\mathrm{A}$ allele and CP individuals, just as there was with the CC genotype and healthy individuals. These results further showed that IL-10-592 $(-590,-597)$ A allele may be the susceptible factor for the onset of CP while CC genotype may be the protective effect against CP occurrence (OR=0.62, 95\% $\mathrm{CI}=0.44-0.87)$. Among the related 11 studies, five of them, reported by Jaradat et al. [24], Sumer et al. [17], Claudino et al. [18], Garlet et al. [23], and Toker et al. [33], showed that the A allele occurred significantly more frequently in the CP population than in the control group, respectively, while another four studies reported by Scapoli et al. [26], ScarelCaminaga et al. [16], Silveira et al. [27], and Toker et al. [30] also described these trends, respectively. Studies reported by Sumer et al. [17], Claudino et al. [18], ScarelCaminaga et al. [16], Garlet et al. [23], and Jaradat et al. [24] indicated that the CC genotype at the -592 or -597 positions occurred significantly more frequently in the control group than in the CP group. Additional three studies reported by Moudi et al. [32], Scapoli et al. [26], and Silveira et al. [27] previously present these trends. Therefore, we obtained positive results that were consistent with most other studies. The AA genotype in 3 studies conducted by Sumer et al. [17] and Toker et al. [30, 33] occurred significantly more frequently in the CP group than in the control group. Four studies, those conducted by Scapoli et al. [26], Jaradat et al. [24], Garlet et al. [23], and Claudino et al. [18] presented these trends, but four additional studies carried out by Atanasovska-Stojanovska et al. [22], Moudi et al. [32], Scarel-Caminaga et al. [16], and Silveira et al. [27] did not show these trends. Our present meta-analysis also did not show significantly positive results, suggesting that the AA genotype might not be the risk for $\mathrm{CP}$ in a nonsmoking population. However, the AA genotype might increase the risk for AgP onset in nonsmoker population because our metaanalysis results showed a threefold greater difference between the case and control groups under the AA versus $\mathrm{AC}+\mathrm{CC}$ model for the AgP risk. These results were partially expected, as three related studies performed by Silveira et al. [27], Gorgun et al. [29], and Toker et al. [30] all showed the risk trend.

4.2. Strengths and Limitations. This meta-analysis has several strengths, including an unrestricted search process (including grey literature), duplicate review procedures for the search, sensitivity analysis, and assessments of the risk of bias and the quality of literature. But this meta-analysis has some limitations. As we know, interstudy heterogeneity and publication bias are main limitations associated with metaanalyses. Heterogeneity can be caused by many factors such as race, sample sizes, smoking habits, and deviations of allele 


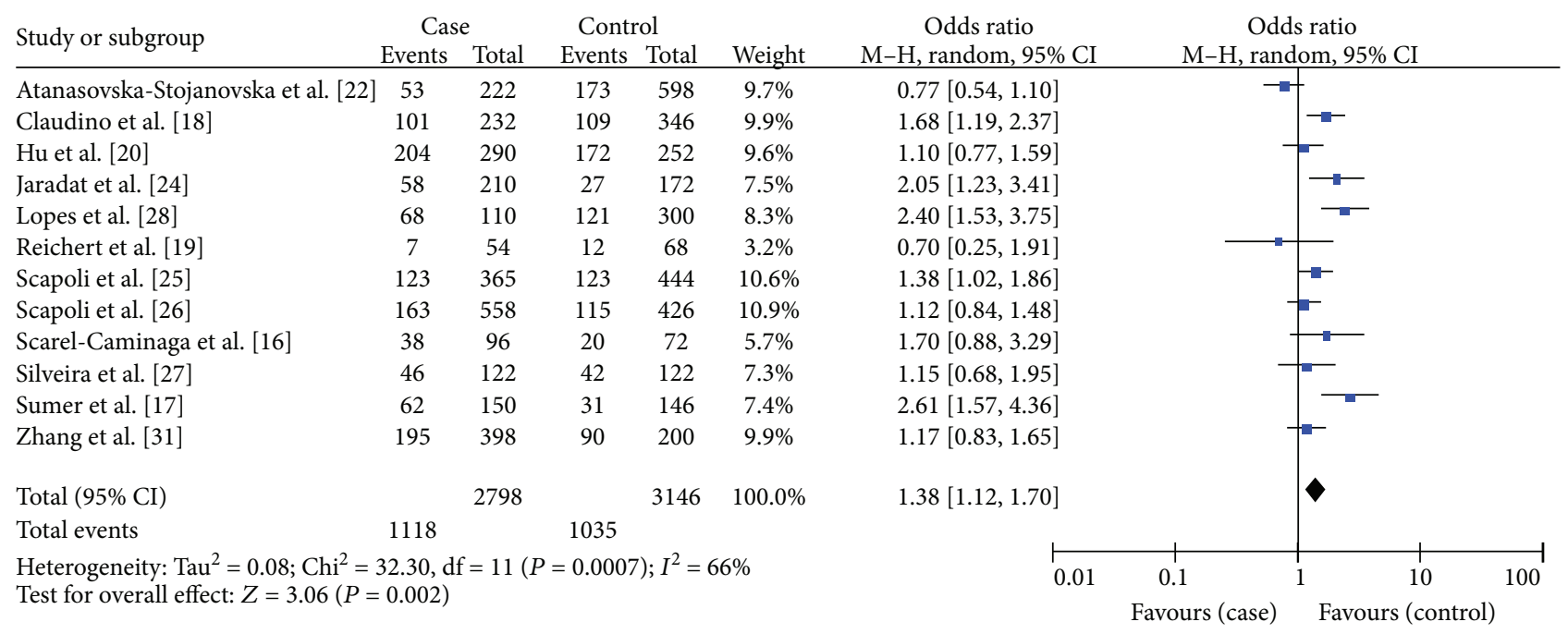

(a)

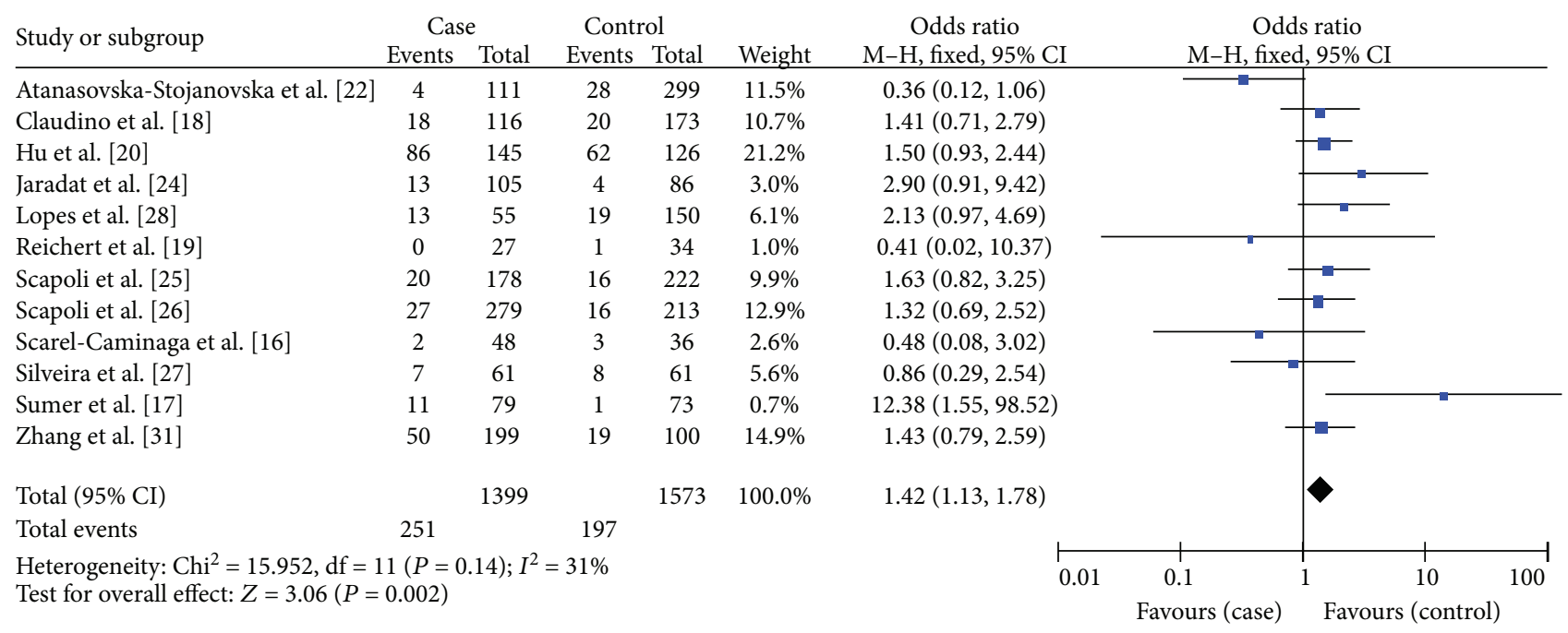

(b)

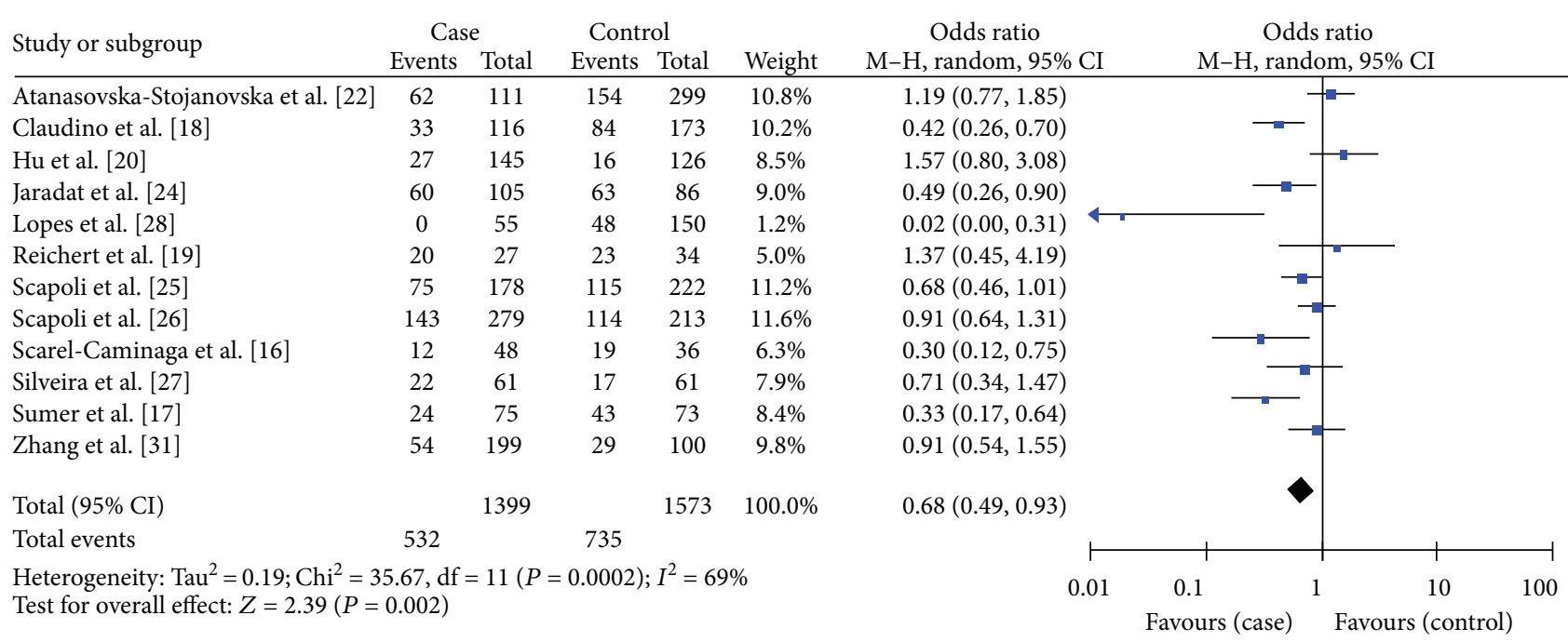

(c)

FIGURE 2: Forest plot of the association between IL-10-592 $(-590,-597) \mathrm{C}>\mathrm{A}$ polymorphisms and chronic periodontitis by excluding the studies deviated from HWE in the control. (a) A allele versus $\mathrm{C}$ allele model. (b) AA versus AC+CC model. (c) CC versus AC+AA model. 


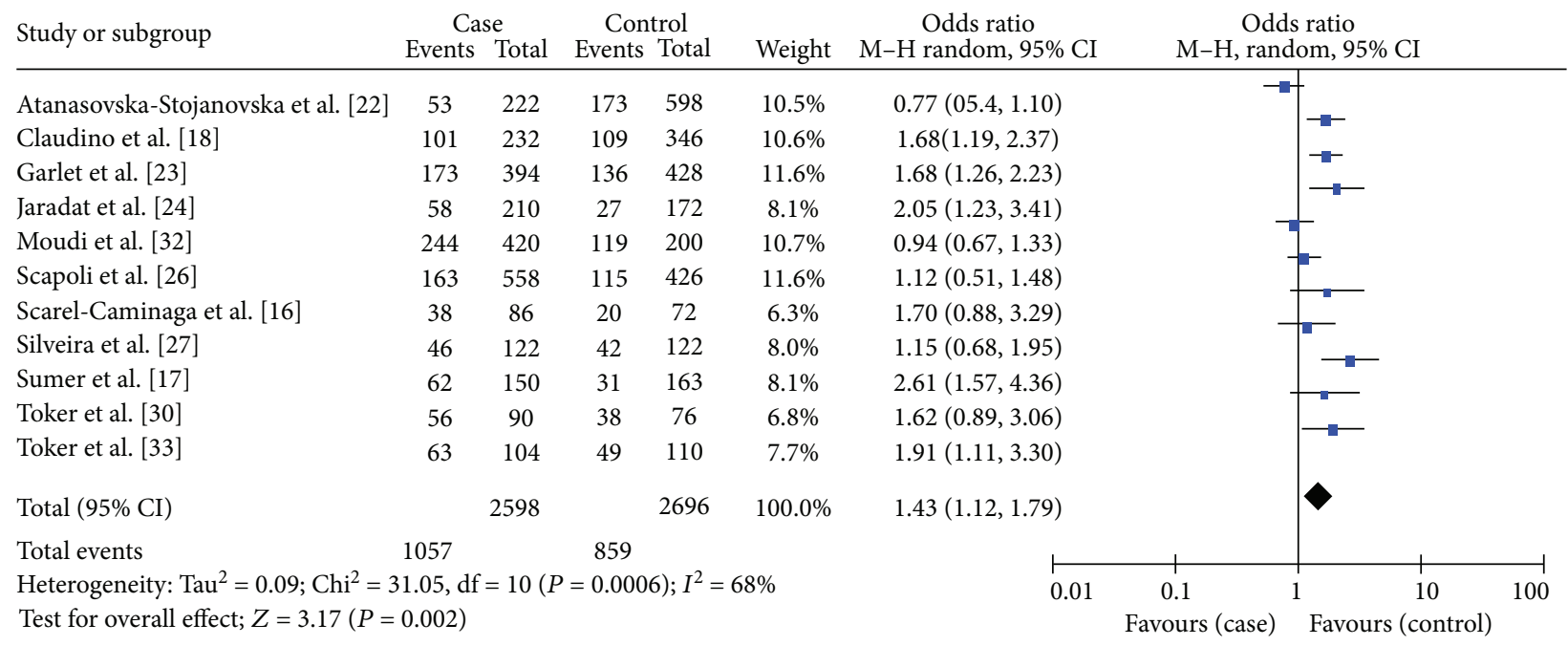

(a)

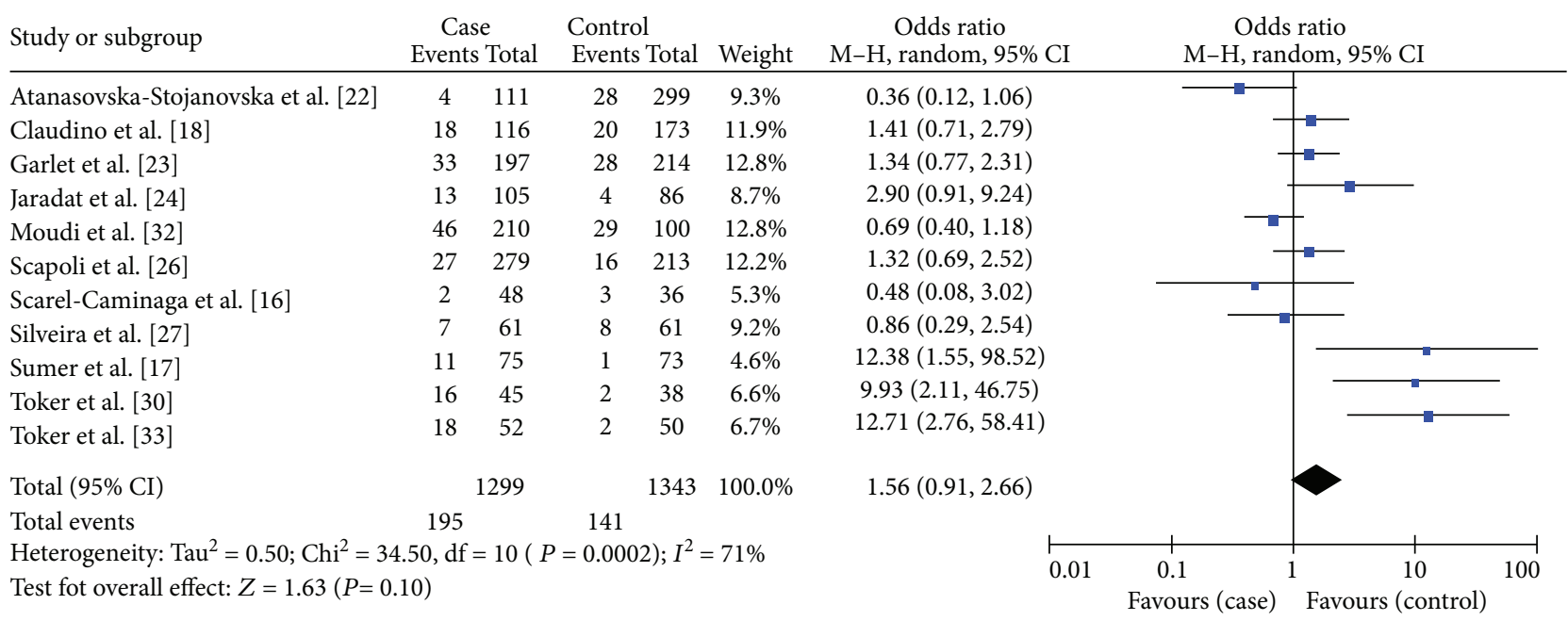

(b)

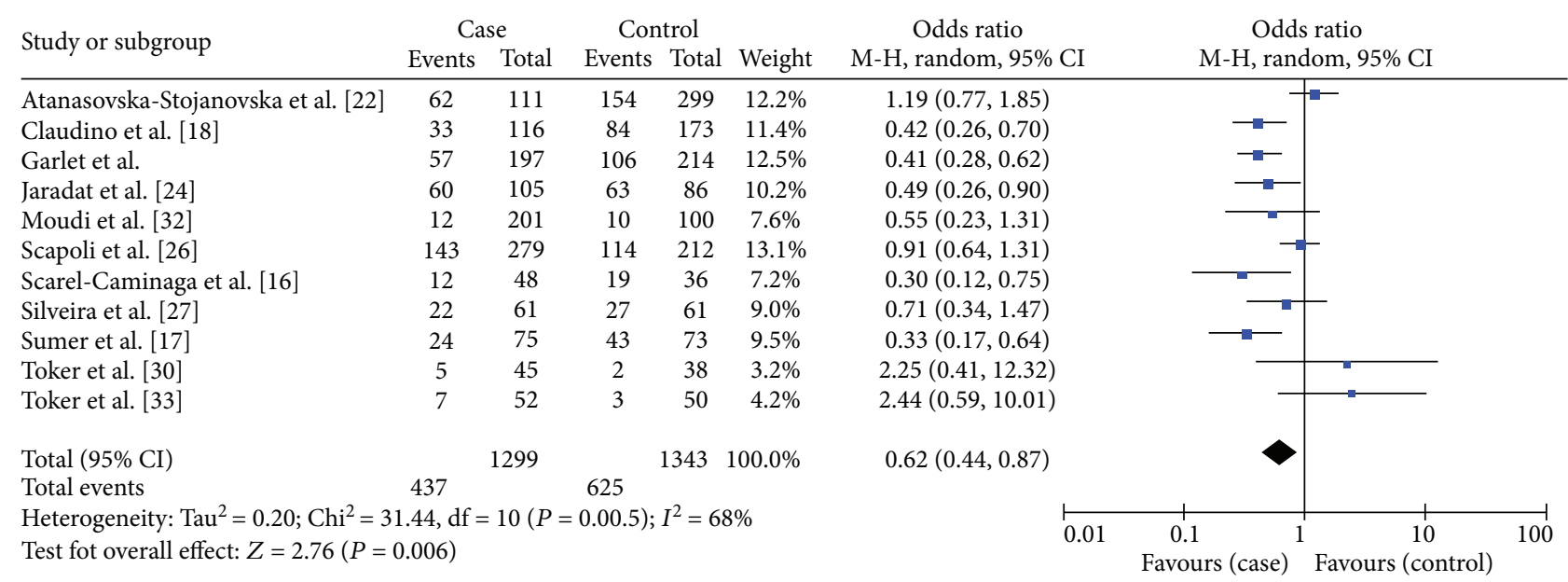

(c)

FIGURE 3: Forest plot of the association between IL-10-592 $(-590,-597)$ C>A polymorphisms and chronic periodontitis in nonsmoking population. (a) A allele versus $\mathrm{C}$ allele model. (b) AA versus AC+CC model. (c) CC versus AC+AA model. 


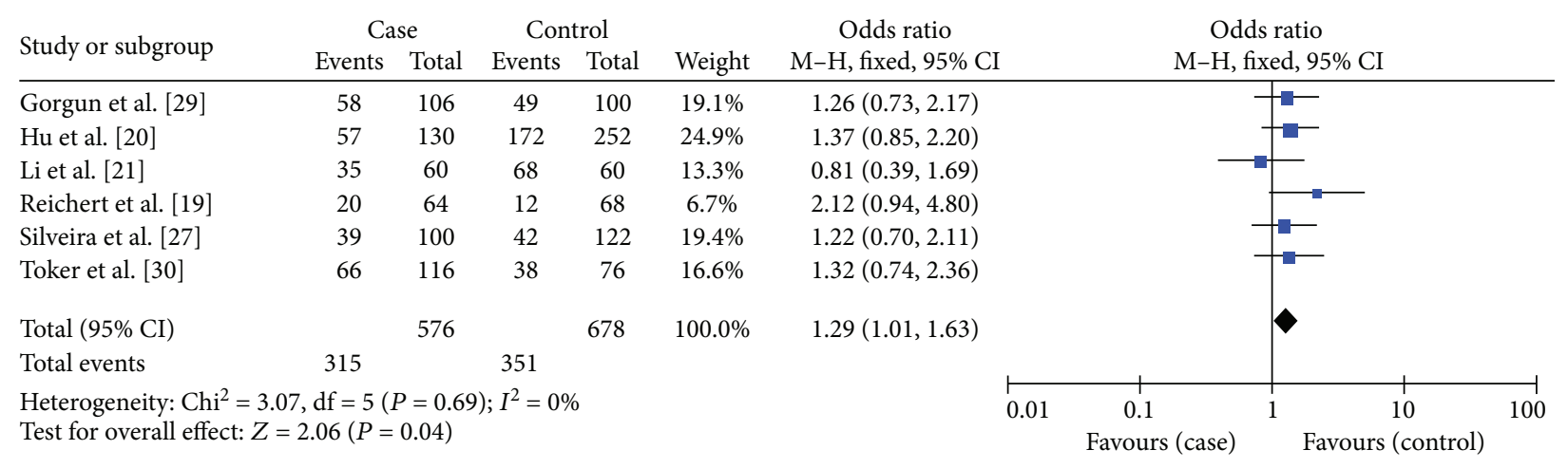

(a)

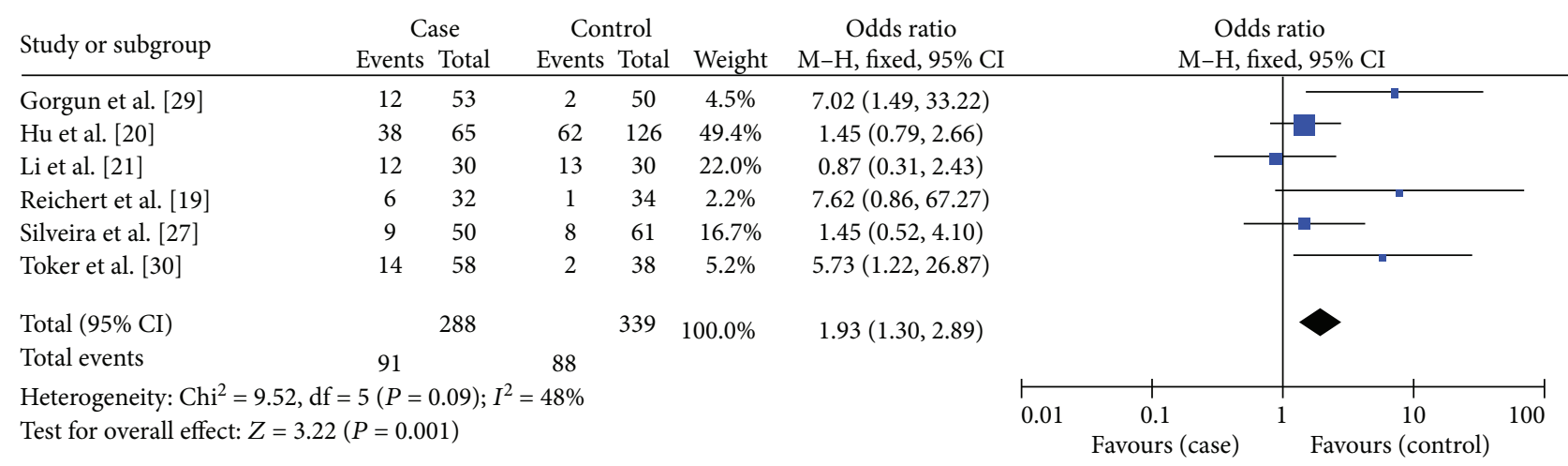

(b)

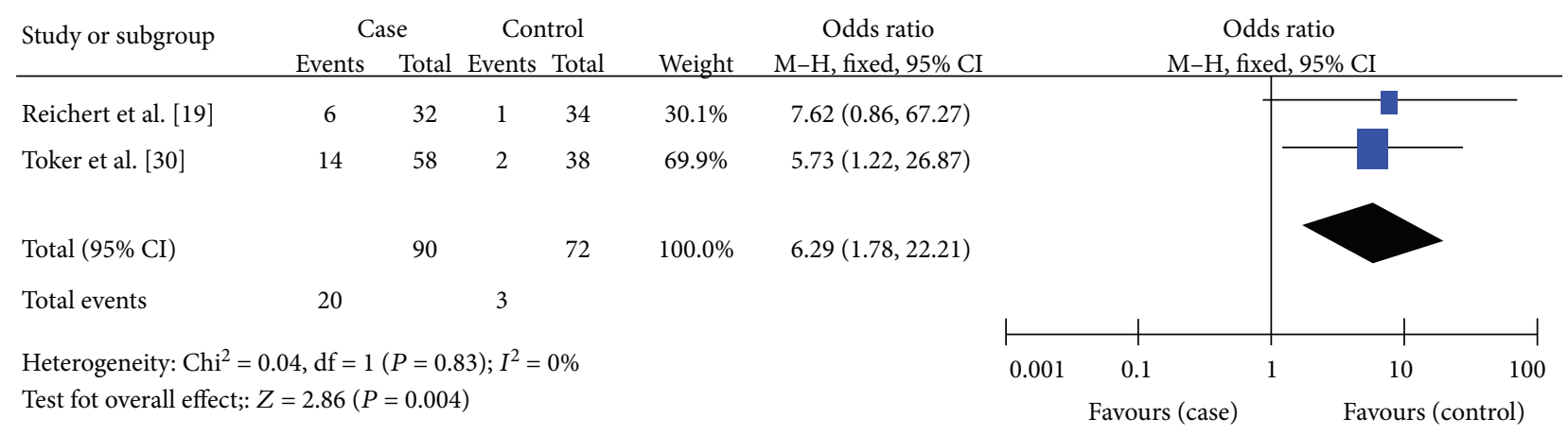

(c)

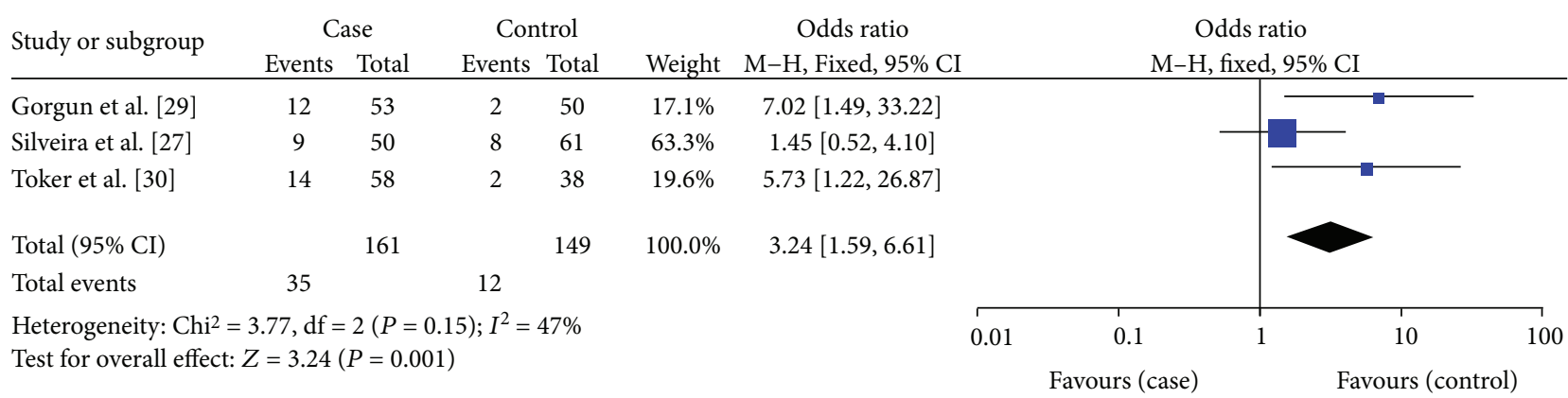

(d)

FIGURE 4: Forest plot of the association between IL-10-592 (-590, -597) A $>$ C polymorphisms and aggressive periodontitis. (a) A allele versus $\mathrm{C}$ allele model. (b) AA versus $\mathrm{AC}+\mathrm{CC}$ model. (c) AA versus $\mathrm{AC}+\mathrm{CC}$ model in Caucasian population. (d) AA versus AC+CC model in nonsmoking population. 
distributions from the HWE [6]. There was obvious heterogeneity in the overall analysis involving $\mathrm{CP}$ individuals. We removed the studies from our analysis that deviated from HWE in the controls and performed the analysis again. Using these refined parameters, we still found that the results displayed higher heterogeneity in the A allele versus $\mathrm{C}$ allele model, as well as in the CC versus AC+AA model. Subgroup analysis based on Caucasian race or nonsmoking population also displayed higher heterogeneity. Further analysis found out that in the A allele versus $\mathrm{C}$ allele model, there was observed heterogeneity in the Atanasovska-Stojanovska et al. study [22], whose control sample sizes was larger, and from the Lopes et al. study [28], in which the pooled OR values were more than two, indicating over two times increased susceptibility to $\mathrm{CP}$. When we concurrently removed the above two studies, the $I^{2}$ value decreased to less than $50 \%$. In the CC versus AC+AA model, the main heterogeneity may have resulted from inclusion of the AtanasovskaStojanovska et al. study [22], which had larger sample sizes in the control group, the Lopes et al. study [28] with zero CC individual in the case group, the Hu et al. study [20] with differential result, and the Scapoli et al. study [26], which had larger sample sizes in its case group. When these studies were removed, the $I^{2}$ value also decreased to less than $50 \%$.

Another factor that we considered in our analysis was publication bias. Publication bias stems from the fact that positive results are much more readily published by journals, whereas negative results tend to be poorly received by journals and are collectively known as "grey literature" $[6,14,15]$. In the present study, we used Egger's test to probe the occurrence of publication bias, and the results indicated apparent publication bias in HWE fulfillment, as well as in the Caucasian population subgroup analysis in the $\mathrm{CP}$ versus controls allele comparison, which may have distorted our present results. We observed the funnel plot asymmetry of the two contrasts and found Atanasovska-Stojanovska et al. study [22], which contained a larger sample size, and Reichert et al. study [19], which comprised a smaller sample size, caused the publication bias. After excluding these two studies, the $P$ value of Egger's test increased to over 0.05 . However, the corresponding pooled $\mathrm{OR}$ values were not substantially altered without the publication bias.

Although a broad search in four different databases was used to find studies for inclusion in our meta-analysis, it is impossible to confirm that all available studies addressing the relationship between IL-10-592 (-590, -597) C>A polymorphisms and periodontitis were included, presenting another major limitation of the meta-analysis.

4.3. Implications for Clinical Practice. Three common single nucleotide polymorphisms (SNPs) in the IL-10 gene promoter $(-1082 \mathrm{~A}>\mathrm{G},-819 \mathrm{C}>\mathrm{T}$, and $-592 \mathrm{C}>\mathrm{A}$ ) show strong linkage disequilibrium and form two common haplotypes, designated as [ATA] and [GCC]. The [ATA] haplotype has been associated with decreased synthesis of IL-10 and is frequently associated with periodontitis [18]. Owing to the linkage disequilibrium, the presence of those haplotypes can be fully determined by the analysis of the IL-10-592 $(-590,-597) \mathrm{C}>\mathrm{A}$ polymorphism, in which the occurrence of the A allele indicates the presence of the [ATA] haplotype [18]. Our findings showed that IL-10-592 (-590, -597) A allele or AA genotype existed extensively in $\mathrm{CP}$ and AgP populations, especially in Caucasian AgP populations. Therefore, the IL-10-592 $(-590,-597)$ A allele or AA genotype may be a putative biomarker for the diagnosis of $\mathrm{CP}$ and AgP. We suggest that when patients are initially diagnosed with periodontitis clinically, testing for IL-10-592 $(-590,-597)$ polymorphisms may be helpful in confirming diagnosis. Doctors and dentists may also routinely consider monitoring the IL-10-592 (-590, -597) A allele or AA genotype in healthy population to prevent the occurrence of $\mathrm{CP}$ and $\mathrm{AgP}$ by recommending prophylactic measures. Such prophylactic measures include no smoking, regularly seeing dentists for professional examination, removal of microbial biofilm, and so forth, brushing teeth twice daily for 2 minutes with a soft toothbrush, brushing the tongue, cleaning the interdental spaces with interdental aids (such as floss or interproximal brushes), using a fluoride toothpaste, and having a balanced diet, among others [39].

\section{Conclusion}

Even considering the limitations of this study, the present meta-analysis supported the hypothesis that IL-10-592 $(-590,-597) \mathrm{C}>\mathrm{A}$ polymorphisms may be associated with $\mathrm{CP}$ and $\mathrm{AgP}$ susceptibility. We not only identified that the IL-10-592 (-590, -597) A alleles and AA genotypes may be a risk factor for the development of $\mathrm{CP}$ and $\mathrm{AgP}$ but also found out that the IL-10-592 (-590, -597) CC genotype may play a protective role in preventing CP. It is noteworthy that the AA genotype was found to be more closely tied to the risk of AgP in Caucasian and nonsmoker population. Thus, IL10-592 $(-590,-597)$ A alleles or AA genotypes may be a putative biomarker for diagnosing CP and AgP. Large-scale studies to further validate our findings should be performed in the future.

\section{Conflicts of Interest}

The authors declare that there are no competing interests regarding the publication of this paper.

\section{Authors' Contributions}

Yao Li searched literature, selected study, analysed data, and drafted the article. Yuejia Deng and Ge Feng participated in the literature search and study selection. Jinglin Song designed this study, interpreted data, and revised the article.

\section{Acknowledgments}

This study was supported by the Program for Innovation Team Building at Institutions of Higher Education in Chongqing in 2016 (Grant no. CXTDG201602006). 


\section{Supplementary Materials}

e-Table 1: Newcastle-Ottawa quality assessment scores for the studies included in the meta-analysis. e-Table 2: sensitivity analysis* for the $\mathrm{A}$ allele versus $\mathrm{C}$ allele model and $\mathrm{CP}$ risk. e-Table 3: sensitivity analysis* for the AA versus AC+CC model and CP risk. e-Table 4: sensitivity analysis* for the $\mathrm{CC}$ versus $\mathrm{AA}+\mathrm{AC}$ model and $\mathrm{CP}$ risk. (Supplementary Materials)

\section{References}

[1] B. S. Michalowicz, D. Aeppli, J. G. Virag et al., "Periodontal findings in adult twins," Journal of Periodontology, vol. 62, no. 5, pp. 293-299, 1991.

[2] B. S. Michalowicz, S. R. Diehl, J. C. Gunsolley et al., "Evidence of a substantial genetic basis for risk of adult periodontitis," Journal of Periodontology, vol. 71, no. 11, pp. 1699-1707, 2000.

[3] K. Erciyas, S. Pehlivan, T. Sever, M. Igci, A. Arslan, and R. Orbak, "Association between TNF- $\alpha$, TGF- $\beta 1$, IL-10, IL-6 and IFN- $\gamma$ gene polymorphisms and generalized aggressive periodontitis," Clinical and Investigative Medicine, vol. 33, no. 2 , p. $85,2010$.

[4] Z. Akram, T. Abduljabbar, M. I. A. Hassan, F. Javed, and F. Vohra, "Cytokine profile in chronic periodontitis patients with and without obesity: a systematic review and meta-analysis," Disease Markers, vol. 2016, Article ID 4801418, 12 pages, 2016.

[5] G. S. Chatzopoulos and V. P. Koidou, "Association between susceptible genotypes to periodontitis and clinical outcomes of periodontal regenerative therapy: a systematic review," Medicina Oral, Patología Oral y Cirugía Bucal, vol. 21, no. 4, pp. e456-e464, 2016.

[6] J. Zhu, B. Guo, M. Fu et al., "Interleukin-6-174 G/C polymorphism contributes to periodontitis susceptibility: an updated meta-analysis of 21 case-control studies," Disease Markers, vol. 2016, Article ID 9612421, 12 pages, 2016.

[7] L. S. Finoti, R. Nepomuceno, S. C. Pigossi, S. C. T. Corbi, R. Secolin, and R. M. Scarel-Caminaga, "Association between interleukin-8 levels and chronic periodontal disease," Medicine, vol. 96, no. 22, article e6932, 2017.

[8] P. M. Preshaw and J. J. Taylor, "How has research into cytokine interactions and their role in driving immune responses impacted our understanding of periodontitis?," Journal of Clinical Periodontology, vol. 38, Supplement 11, pp. 60-84, 2011.

[9] A. J. P. Smith and S. E. Humphries, "Cytokine and cytokine receptor gene polymorphisms and their functionality," Cytokine \& Growth Factor Reviews, vol. 20, no. 1, pp. 43-59, 2009.

[10] S. H. Stein, T. E. Hart, W. H. Hoffman, C. L. Hendrix, C. J. Gustke, and S. C. Watson, "Interleukin-10 promotes anticollagen antibody production in type I diabetic peripheral B lymphocytes," Journal of Periodontal Research, vol. 32, no. 1, pp. 189-195, 1997.

[11] J. M. Kim, C. I. Brannan, N. G. Copeland, N. A. Jenkins, T. A. Khan, and K. W. Moore, "Structure of the mouse IL-10 gene and chromosomal localization of the mouse and human genes," Journal of Immunology, vol. 148, no. 11, pp. 36183623, 1992.

[12] D. M. Turner, D. M. Williams, D. Sankaran, M. Lazarus, P. J. Sinnott, and I. V. Hutchinson, "An investigation of polymorphism in the interleukin-10 gene promoter," European Journal of Immunogenetics, vol. 24, no. 1, pp. 1-8, 1997.

[13] D. Kube, C. Platzer, A. von Knethen et al., "Isolation of the human interleukin 10 promoter: characterization of the promoter activity in Burkitt's lymphoma cell lines," Cytokine, vol. 7, no. 1, pp. 1-7, 1995.

[14] Q. Zhong, C. Ding, M. Wang, Y. Sun, and Y. Xu, "Interleukin10 gene polymorphisms and chronic/aggressive periodontitis susceptibility: a meta-analysis based on 14 case-control studies," Cytokine, vol. 60, no. 1, pp. 47-54, 2012.

[15] C. M. Albuquerque, A. J. Cortinhas, F. J. Morinha, J. C. Leitão, C. A. Viegas, and E. M. Bastos, "Association of the IL-10 polymorphisms and periodontitis: a meta-analysis," Molecular Biology Reports, vol. 39, no. 10, pp. 9319-9329, 2012.

[16] R. M. Scarel-Caminaga, P. C. Trevilatto, A. P. Souza, R. B. Brito, L. E. A. Camargo, and S. R. P. Line, "Interleukin 10 gene promoter polymorphisms are associated with chronic periodontitis," Journal of Clinical Periodontology, vol. 31, no. 6, pp. 443-448, 2004.

[17] A. P. Sumer, N. Kara, G. C. Keles, S. Gunes, H. Koprulu, and H. Bagci, "Association of interleukin-10 gene polymorphisms with severe generalized chronic periodontitis," Journal of Periodontology, vol. 78, no. 3, pp. 493-497, 2007.

[18] M. Claudino, A. P. F. Trombone, C. R. Cardoso et al., "The broad effects of the functional IL-10 promoter-592 polymorphism: modulation of IL-10, TIMP-3, and OPG expression and their association with periodontal disease outcome," Journal of Leukocyte Biology, vol. 84, no. 6, pp. 1565-1573, 2008.

[19] S. Reichert, H. K. Machulla, J. Klapproth et al., "The interleukin-10 promoter haplotype ATA is a putative risk factor for aggressive periodontitis," Journal of Periodontal Research, vol. 43, no. 1, pp. 40-47, 2008.

[20] K. F. Hu, K. C. Huang, Y. P. Ho et al., "Interleukin-10 (-592 C/ A) and interleukin-12B (+16974 A/C) gene polymorphisms and the interleukin-10 ATA haplotype are associated with periodontitis in a Taiwanese population," Journal of Periodontal Research, vol. 44, no. 3, pp. 378-385, 2009.

[21] Y. Li, H. Zhao, and J. C. Zhang, "Interleukin-10 gene promoter polymorphism in Chinese patients with generalized aggressive periodontitis," Journal of Dental Prevention and Treatment, vol. 17, no. 10, pp. 472-475, 2009.

[22] A. Atanasovska-Stojanovska, D. Trajkov, M. Popovska, and M. Spiroski, "IL10 -1082, IL10 -819 and IL10 -592 polymorphisms are associated with chronic periodontitis in a Macedonian population," Human Immunology, vol. 73, no. 7, pp. 753-758, 2012.

[23] G. P. Garlet, A. P. F. Trombone, R. Menezes et al., "The use of chronic gingivitis as reference status increases the power and odds of periodontitis genetic studies-a proposal based in the exposure concept and clearer resistance and susceptibility phenotypes definition," Journal of Clinical Periodontology, vol. 39, no. 4, pp. 323-332, 2012.

[24] S. M. Jaradat, K. T. Ababneh, S. A. Jaradat et al., "Association of interleukin-10 gene promoter polymorphisms with chronic and aggressive periodontitis," Oral Diseases, vol. 18, no. 3, pp. 271-279, 2012.

[25] L. Scapoli, A. Girardi, A. Palmieri et al., "IL6 and IL10 are genetic susceptibility factors of periodontal disease," Dental Research Journal, vol. 9, Supplement 2, pp. s197-s201, 2012.

[26] L. Scapoli, A. Girardi, A. Palmieri et al., "Interleukin-6 gene polymorphism modulates the risk of periodontal diseases," 
Journal of Biological Regulators and Homeostatic Agents, vol. 29, 3 Supplement 1, pp. 111-116, 2015.

[27] V. R. S. Silveira, S. C. Pigossi, R. M. Scarel-Caminaga, J. A. Cirelli, R. Rêgo, and N. A. P. Nogueira, "Analysis of polymorphisms in interleukin 10, NOS2A, and ESR2 genes in chronic and aggressive periodontitis," Brazilian Oral Research, vol. 30, no. 1, p. e105, 2016.

[28] C. B. Lopes, B. RFF, B. RMR et al., "Effect of ancestry on interleukin-10 haplotypes in chronic periodontitis," Frontiers in Bioscience, vol. 9, no. 2, pp. 276-285, 2017.

[29] E. P. Gorgun, H. Toker, E. M. Korkmaz, O. Poyraz, and Cumhuriyet University, Turkey, "IL-6 and IL-10 gene polymorphisms in patients with aggressive periodontitis: effects on GCF, serum and clinic parameters," Brazilian Oral Research, vol. 31, 2017.

[30] H. Toker, E. P. Görgün, and E. M. Korkmaz, “Analysis of IL-6, IL-10 and NF-KB gene polymorphisms in aggressive and chronic periodontitis," Central European Journal of Public Health, vol. 25, no. 2, pp. 157-162, 2017.

[31] Y. H. Zhang, P. Huang, J. Lin, and J. Zhao, "Correlation between interleukin-10 polymorphisms and susceptibility to chronic periodontitis among Uygur adults in the Moyu area," West Chinese Journal of Stomatology, vol. 35, no. 5, pp. 514519, 2017.

[32] B. Moudi, Z. Heidari, H. Mahmoudzadeh-Sagheb, and M. Moudi, "Analysis of interleukin-10 gene polymorphisms in patients with chronic periodontitis and healthy controls," Dental Research Journal, vol. 15, no. 1, pp. 71-79, 2018.

[33] H. Toker, E. P. Gorgun, E. M. Korkmaz, H. B. Yüce, and O. Poyraz, "The effects of IL-10 gene polymorphism on serum, and gingival crevicular fluid levels of IL-6 and IL-10 in chronic periodontitis," Journal of Applied Oral Science, vol. 26, 2018.

[34] L. Shamseer, D. Moher, M. Clarke et al., "Preferred reporting items for systematic review and meta-analysis protocols (PRISMA-P) 2015: elaboration and explanation," BMJ, vol. 349, no. jan02 1, 2015.

[35] G. A. Wells, B. Shea, D. O'Connell et al., "The NewcastleOttawa Scale (NOS) for assessing the quality of nonrandomized studies in meta-analyses," 2011, http://www.ohri.ca/ programs/clinical_epidemiology/oxford.asp.

[36] J. D. Sutton, M. L. Salas Martinez, and M. M. Gerkovich, "Environmental tobacco smoke and periodontitis in United States non-smokers, 2009 to 2012," Journal of Periodontology, vol. 88, no. 6, pp. 565-574, 2017.

[37] S. L. Tomar and S. Asma, "Smoking-attributable periodontitis in the United States: findings from NHANES III. National Health and Nutrition Examination Survey," Journal of Periodontology, vol. 71, no. 5, pp. 743-751, 2000.

[38] F. R. M. Leite, G. G. Nascimento, F. Scheutz, and R. López, "Effect of smoking on periodontitis: a systematic review and meta-regression," American Journal of Preventive Medicine, vol. 54, no. 6, pp. 831-841, 2018.

[39] D. F. Kinane, P. G. Stathopoulou, and P. N. Papapanou, "Periodontal diseases," Nature Reviews Disease Primers, vol. 3, article 17038, 2017. 


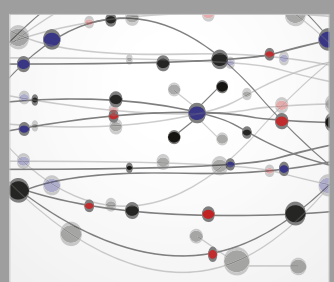

The Scientific World Journal
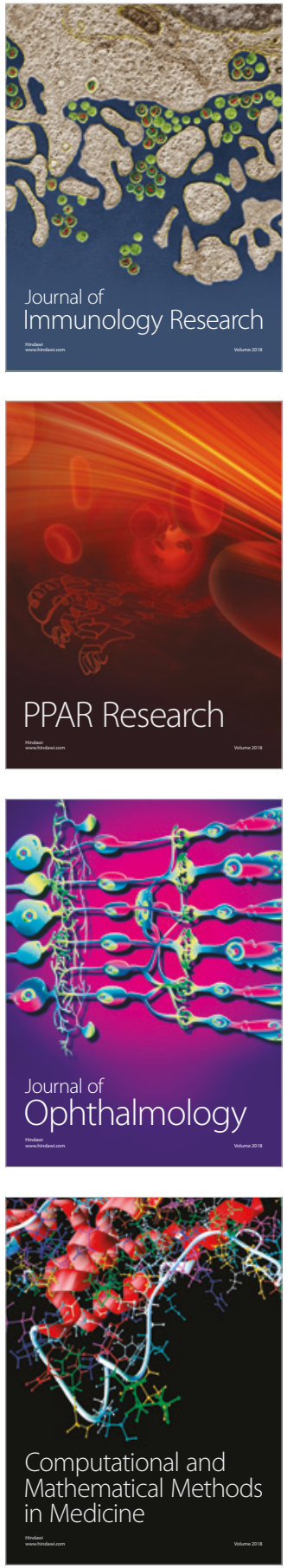

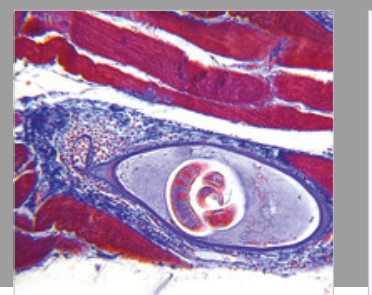

Gastroenterology Research and Practice

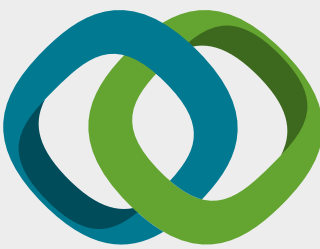

\section{Hindawi}

Submit your manuscripts at

www.hindawi.com
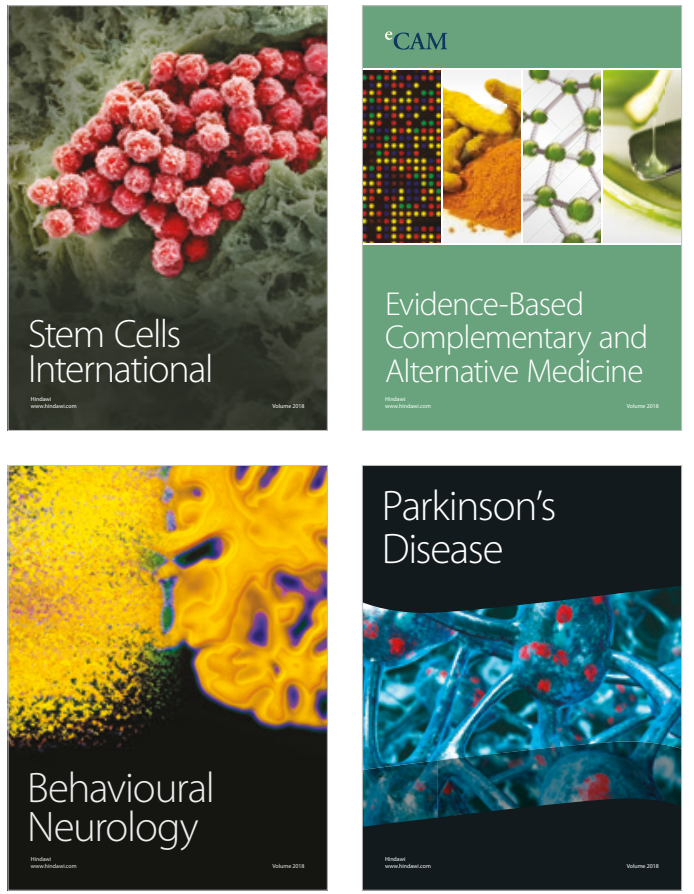

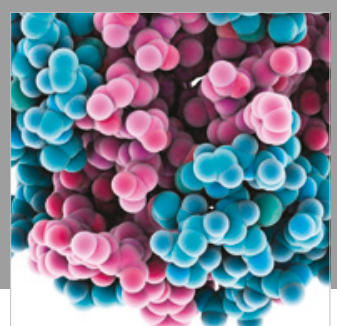

ournal of

Diabetes Research

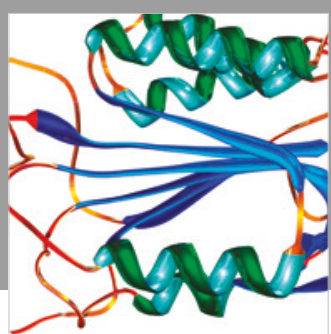

Disease Markers
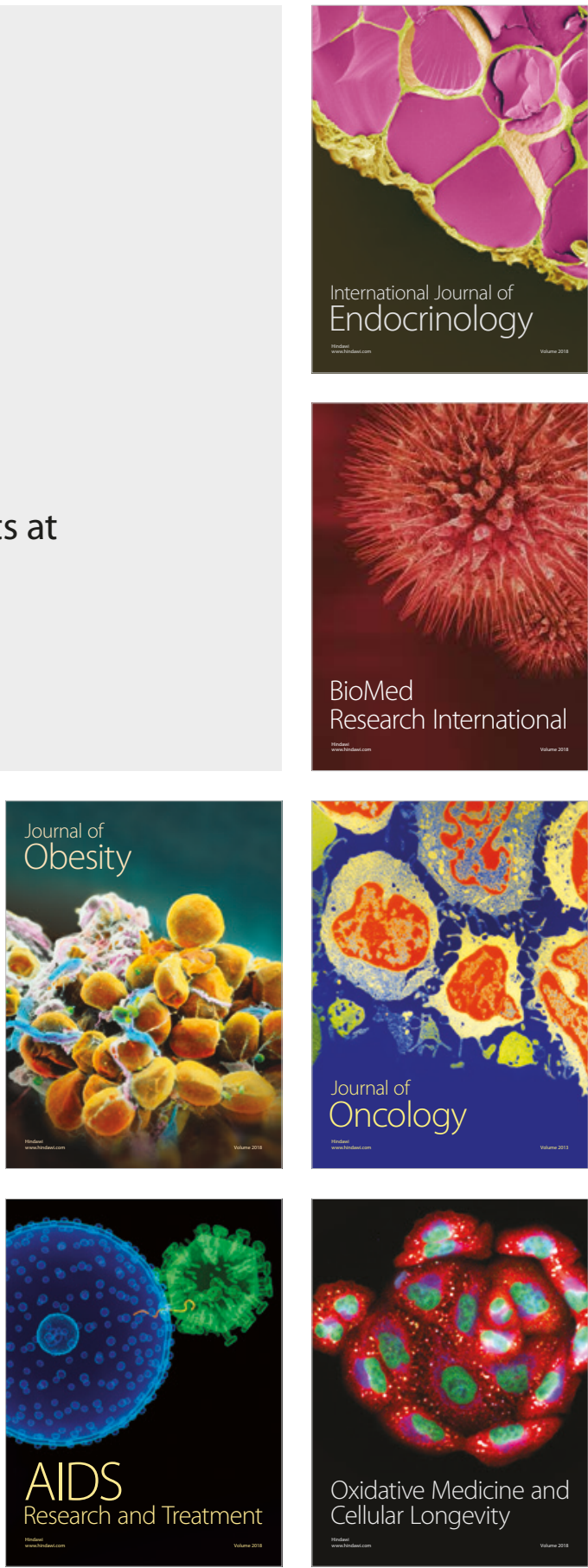